\title{
Measurements of Water Vapor Profiles With Compact DIAL in The TOKYO METROPOLITAN AREA \\ Makoto Abo $^{1^{*}}$, Tetsu Sakai ${ }^{2}$, Phong Pham Le Hoai ${ }^{1}$, Yasukuni Shibata ${ }^{1}$, Chikao Nagasawa ${ }^{1}$ \\ ${ }^{I}$ Tokyo Metropolitan University, Japan, *Email: abo@tmu.ac.jp \\ ${ }^{2}$ MRI, Japan
}

\begin{abstract}
In recent years, the frequency of occurrence of locally heavy rainfall that can cause extensive damages, has been increasing in Japan. For early prediction of heavy rainfall, it is useful to measure the water vapor vertical distribution upwind cumulus convection beforehand. For that purpose, we have been developing compact water vapor differential absorption lidar (DIAL).

We show the results of the measurements with lidar in summer when the local heavy rainfall frequently occurs in Japan. We also show the preliminary result of the assimilation of the lidar data to the numerical model and impact on the heavy rainfall prediction.
\end{abstract}

\section{INTRODUCTION}

Locally heavy rainfall is a severe weather hazards to affect urban areas in Japan. For early prediction of the heavy rainfall, numerical weather model is employed using the conventional meteorological station data. However, the lead time and accuracy of the prediction are limited because of the coarse spatial and temporal resolutions of the data. To improve them, it is useful to measure the water vapor distribution upwind of cumulus convection beforehand and assimilate the data into the model. Figure 1 shows schematic of this study.

For that purpose, we have developed compact and mobile diode-laser-based differential absorption lidar (DIAL) that can measure the vertical distribution of water vapor in the lower troposphere.

\section{DIAL SYSTEM}

The DIAL employs two distributed Bragg reflector (DBR) lasers operating at $829.054 \mathrm{~nm}$ for the online wavelength and $829.124 \mathrm{~nm}$ for the offline wavelength with tapered semiconductor optical amplifier (TSOA) in a master oscillator power amplifier (MOPA) configuration. The lidar measure the vertical distribution of the water vapor in the lower troposphere with a vertical resolution of a few tenths of a meter and temporal resolution of a few tenths of a minute.

Table 1 Specifications of DIAL system.

\begin{tabular}{|c|c|}
\hline Transmitter : & \\
\hline Laser & $\begin{array}{l}\text { DBR diode laser } \mathrm{x} 2 \text { (seed } \\
\text { laser), } 80 \mathrm{~mW}+\mathrm{TSOA}\end{array}$ \\
\hline \multirow[t]{2}{*}{ Wavelength } & $829.124 \mathrm{~nm}$ (Off-line) \\
\hline & $829.054 \mathrm{~nm}$ (On-line) \\
\hline Pulse Energy & $4 \mathrm{uJ}$ \\
\hline Repetition & $10 \mathrm{kHz}$ \\
\hline \multicolumn{2}{|l|}{ Receiver : } \\
\hline Telescope & Cassegrain \\
\hline Diameter & $35 \mathrm{~cm}$ \\
\hline Field of View & $0.25 \sim 2.8 \mathrm{mrad}$ (adjustable) \\
\hline \multirow[t]{2}{*}{ Detector } & PMT \\
\hline & (Hamamatsu H9422P-50) \\
\hline Operation & Photon Counting \\
\hline \multicolumn{2}{|l|}{ Interference } \\
\hline Filter & \\
\hline $\begin{array}{c}\text { Center } \\
\text { wavelength }\end{array}$ & $829.11 \mathrm{~nm}$ \\
\hline FWHM & $0.275 \mathrm{~nm}$ \\
\hline Transmission & $47 \%$ \\
\hline
\end{tabular}




\section{MEASUREMENT RESULTS}

We show the results of the $24 \mathrm{H}$ continuous measurements with lidar in summer (26 August 2016) when the local heavy rainfall frequently occurs in Japan in Figure 2.
Figure 3 shows the results of comparison with JMA mesoscale analysis (MSM) and radiosonde at Tsukuba, $80 \mathrm{~km}$ northeast from the lidar observation site Hino.

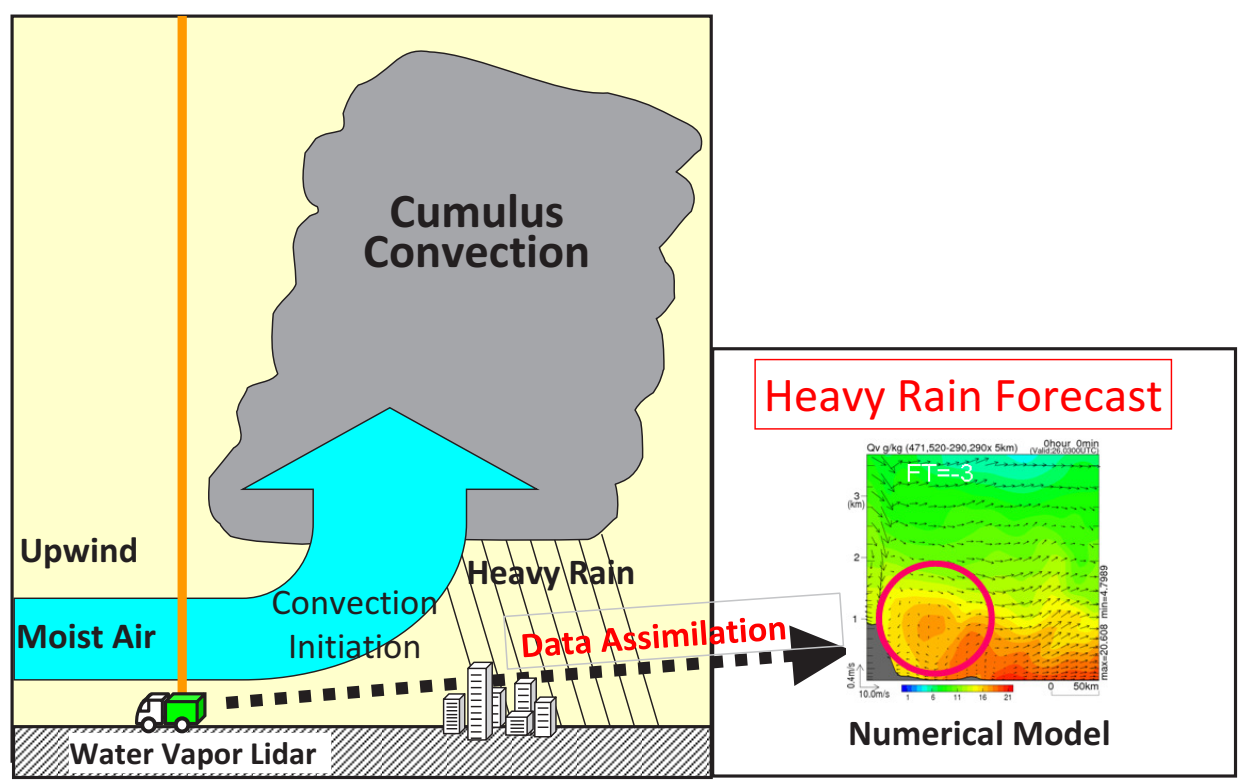

Figure 1. Schematic of this study.

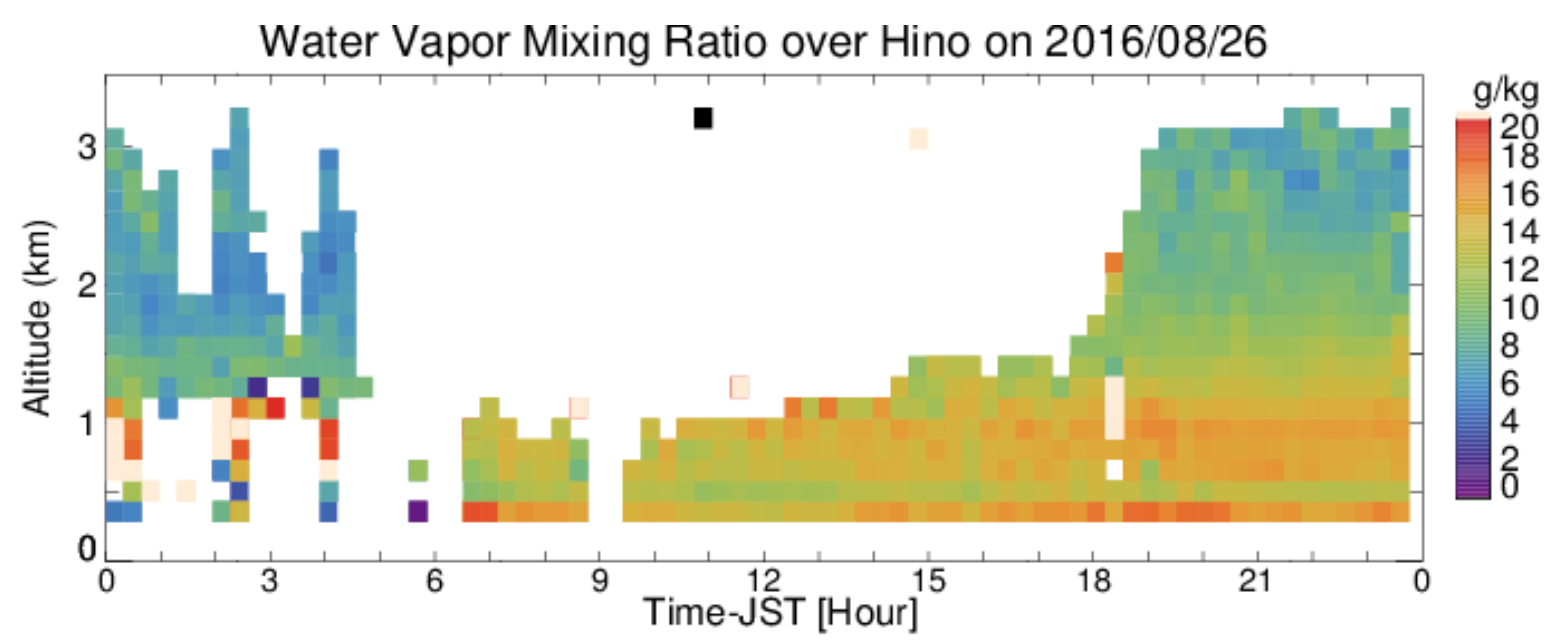

Figure 2. Temporal and height cross section of water vapor mixing ratio obtained with compact DIAL over Hino $\left(35.7^{\circ} \mathrm{N}, 139.4^{\circ} \mathrm{E}\right)$ on 26 August 2016. 

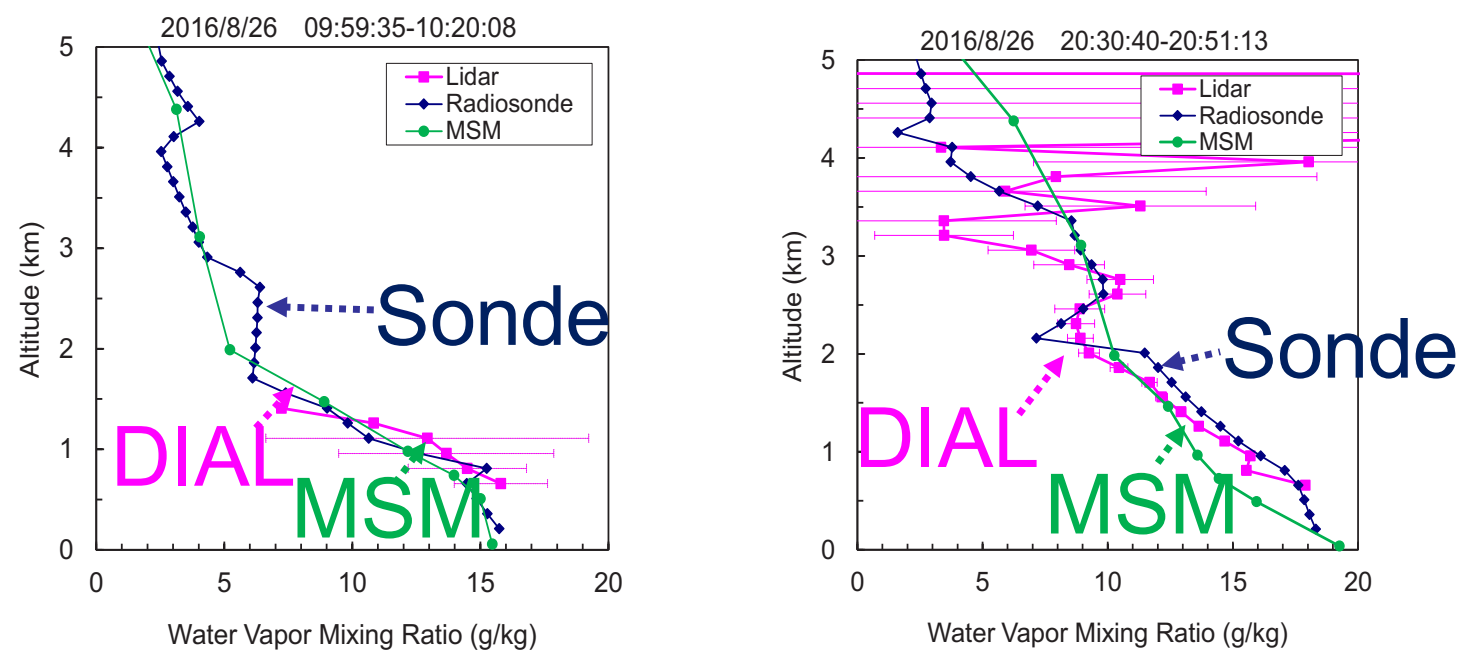

Figure 3 The results of comparison with JMA mesoscale analysis (MSM) and radiosonde at Tsukuba (80 $\mathrm{km}$ northeast).

\section{Strategy:}

\section{Observation systłem simulation \\ experiment (OSSE)}

\section{Deploy lidar to the high-impact observation point}

Take water vapor profiles

\begin{tabular}{l}
$\begin{array}{l}\text { Assimilate lidar } \\
\text { data into JMA } \\
\text { nonhydrostatic } \\
\text { mesosocal model }\end{array}$ \\
\hline \\
\hline $\begin{array}{l}\text { Early prediction of } \\
\text { heavy rainfall }\end{array}$ \\
\hline
\end{tabular}

Figure 4. Strategy of early prediction of the heavy rainfall with numerical weather model and water vapor profiles observed by lidar. 


\section{CONCLUSIONS}

We have been developing water vapor lidars for local heavy rainfalls forecast. Now measurement range is $0.5-3 \mathrm{~km}$ in night time and $1 \mathrm{~km}$ in daytime with $150 \mathrm{~m}$ vertical and $20 \mathrm{~min}$ time resolution with uncertainty within $30 \%$.

We are charanging to increase daytime measurement range to $3 \mathrm{~km}$ for DIAL using etalon and increasing laser power.

Next step, we are planning to conduct field experiment in Tokyo in the summer of 2017 and to assimilate the lidar data to mesoscale model and study the impact on it.

\section{ACKNOWLEDGEMENTS}

This work was supported by JSPS KAKENHI Grant Number JP26282115.

\section{References}

[1] Le Hoai, P.P., M. Abo, T. Sakai (2016): Development of field-deployable Diode-laserbased water vapor DIAL, EPJ Web of Conferences 119 05011, doi: 10.1051/epjconf/20161190501.

[2] Repasky, K., D. Moen,, S. Spuler, A. Nehrir, and J. Carlsten (2013): Progress towards an autonomous field deployable diode laser-based differential absorption lidar (DIAL) for profiling water vapor in the lower troposphere, Remote Sens., 5, 6241-6259, doi:10.3390/rs5126241.

[3] Spuler, S. M., Repasky, K. S., Morley, B., Moen, D., Hayman, M., and Nehrir, A. R.(2015): Fielddeployable diode-laser-based differential absorption lidar (DIAL) for profiling water vapor, Atmos. Meas. Tech., 8, 1073-1087, doi:10.5194/amt-8-1073-2015. 